\title{
What Is Most Important in Rheumatoid Arthritis Treatment - Where You Are, Who You Are, or Where You Are Going?
}

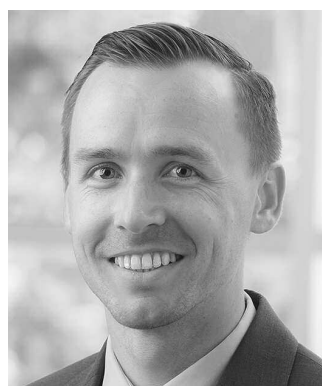

The treatment of rheumatoid arthritis (RA) has been revolutionized by the expansion of conventional (c) and biologic (b) disease-modifying antirheumatic drug (DMARD) choices and the early aggressive treatment of RA to a target of remission or low disease activity, an approach endorsed in major RA treatment guidelines ${ }^{1,2}$. But if you search these guidelines for the words sex, gender, man, woman, men, women, male, and female, you will find these words appear only twice - once in a figure legend describing hepatitis B risk factors and the other in the title of a reference. While sex is not influencing RA treatment recommendations, is it influencing RA treatment choices in the real-world setting? In this issue of The Journal, Bergstra and colleagues asked whether sex differences exist in the selection of initial RA treatments and whether sex influences treatment response ${ }^{3}$.

Bergstra and colleagues used data from the Measurement of Efficacy of Treatment in the Era of Outcome in Rheumatology (METEOR) registry, an international observational registry that records data from routine clinical practice truly a real- "world" study. The authors selected over 5000 patients with RA diagnosed in the last 3 months who were not in Disease Activity Score (DAS) remission and were initiating their first DMARD. The authors evaluated initial treatment patterns: both general approaches (e.g., monotherapy vs combination therapy \pm glucocorticoids) and specific DMARD within these general approaches. Subsequently, they assessed the influence of sex on treatment response, measured by time to switching DMARD and trajectories of the DAS and Health Assessment Questionnaire (HAQ) scores. They found that general approaches in initial RA management were identical between the sexes, but they detected differences in the choice of specific DMARD. Men were more likely than women to start a regimen that contained methotrexate (MTX) or sulfasalazine (SSZ), and women were more likely to start a regimen that included hydroxychloroquine (HCQ). Despite these initial treatment differences, treatment response among women was com- parable to that of men, with equivalent time to switching DMARD and HAQ trajectories. The authors did find higher DAS scores over time in women, but this was only among those initially receiving combination cDMARD therapy ( $\sim 21 \%$ of the registry). The authors concluded that women receive a slightly less aggressive treatment approach than men, but the clinical response is analogous to that of men.

This international study provides an opportunity to contrast initial treatments not only between the sexes, but also across countries. Table 1 shows frequency of DMARD use (MTX, SSZ, HCQ) by sex within each country contributing $>100$ individuals $^{3}$. Specific DMARD use was highly variable across countries. There was a lower frequency of MTX use for both men and women in the Netherlands and Ireland (40-50\%) compared to other countries sampled (57-97\%). These 2 countries, as well as the United Kingdom and India, had among the highest frequency of initial SSZ use (14-56\%). India and the United Kingdom also had the highest initial use of HCQ (39-59\%). Across countries, there was also substantial heterogeneity for sex differences in DMARD use. There was a lower frequency of MTX use among women in South Africa, the United States, Portugal, and Mexico (though only 11 men from Mexico were included), but a higher frequency of MTX use among women in Ireland. Women had a lower frequency of SSZ use in India and Ireland and a higher frequency of HCQ use in the United States, the Netherlands, India, and Ireland. These findings are intriguing and illustrate the need to consider sex differences in the context of the country of residence. However, drawing firm conclusions about sex differences in initial RA treatment is limited by small sample sizes in many of these strata.

Bergstra and colleagues' study is among the first to observe differences in RA treatment patterns between men and women. Discordant treatment patterns were also observed in the Consortium of Rheumatology Researchers of North America (Corrona), but women appeared to be

See Sex differences in RA treatment, page 1361

Personal non-commercial use only. The Journal of Rheumatology Copyright (C) 2018 . All rights reserved. 
Table 1. Methotrexate, sulfasalazine, and hydroxychloroquine use by sex within each country*.

\begin{tabular}{|c|c|c|c|c|c|c|c|c|}
\hline \multirow[b]{2}{*}{ Country } & \multicolumn{2}{|c|}{ Sample Size } & \multicolumn{2}{|c|}{ Methotrexate } & \multicolumn{2}{|c|}{ Sulfasalazine } & \multicolumn{2}{|c|}{ Hydroxychloroquine } \\
\hline & Men & Women & Men & Women & Men & Women & Men & Women \\
\hline South Africa & $74(16.9)$ & $364(83.1)$ & $72(97.3)$ & $329(90.7)$ & $1(1.4)$ & $8(2.2)$ & $9(12.2)$ & $52(14.3)$ \\
\hline USA & $44(27.5)$ & $116(72.5)$ & $32(72.7)$ & $75(64.7)$ & $1(2.3)$ & $4(3.4)$ & $5(11.4)$ & $40(34.5)$ \\
\hline Portugal & $96(27.4)$ & $254(72.6)$ & $73(76.0)$ & $174(68.5)$ & $6(6.3)$ & $14(5.5)$ & $10(10.4)$ & $29(11.4)$ \\
\hline Netherlands & $173(31.9)$ & $370(68.1)$ & $70(40.5)$ & $157(42.4)$ & $24(13.9)$ & $60(16.2)$ & $24(13.9)$ & $95(25.7)$ \\
\hline Mexico & $11(8.5)$ & $119(91.5)$ & $10(90.9)$ & $68(57.1)$ & $0(0)$ & $18(15.1)$ & $0(0)$ & $6(5.0)$ \\
\hline India & $493(16.0)$ & $2580(84.0)$ & $342(69.4)$ & $1722(67.0)$ & $146(29.6)$ & $506(19.6)$ & $191(38.7)$ & $1332(51.6)$ \\
\hline Ireland & $61(28.4)$ & $154(81.6)$ & $24(39.3)$ & $78(50.6)$ & $34(55.7)$ & $51(33.1)$ & $0(0)$ & $15(9.7)$ \\
\hline UK & $153(35.9)$ & $273(63.1)$ & $125(81.7)$ & 227 (83.2) & $74(48.4)$ & $122(44.7)$ & $82(53.6)$ & $160(58.6)$ \\
\hline
\end{tabular}

*Data from Supplementary Tables 2-93. Values are n $(\%)$.

treated more aggressively based on greater tumor necrosis factor inhibitor (TNFi) use and less "weak" DMARD use ${ }^{4}$. The remaining studies have largely found similar treatment patterns between men and women. In the Quantitative Standard Monitoring of Patients with RA program, another large international RA registry, there was an equal proportion of men and women with established RA receiving MTX, prednisone, and bDMARD ${ }^{5}$. In early and established RA studies from Sweden, men and women had similar rates of MTX, SSZ, bDMARD, other DMARD, and steroid use $\mathrm{e}^{6,7,8,9}$. In the Danish biologic (DANBIO) registry, a similar proportion of men and women with early and established RA were receiving $\mathrm{MTX}^{10}$. Finally, in the French Orencia and Rheumatoid Arthritis registry, men and women had a similar frequency of DMARD, MTX, steroid, and bDMARD use ${ }^{11}$. To reconcile these discrepant findings, there are several unique attributes to Bergstra's study that should be considered. First, this study focused on the initial RA treatment strategy in newly diagnosed patients, whereas many of the prior studies evaluated treatments later in the disease course. Second, this study assessed both general RA treatment regimens and specific DMARD nested within these regimens, rather than overall DMARD use. Finally, this was an international study with $>50 \%$ of the participants residing in India, a country not included in the aforementioned studies.

Two important questions arise from the observation of initial treatment differences between the sexes. First, what is the effect on patient outcomes? Reassuringly, despite differences in initial treatments between the sexes, the regimens appeared to be similarly effective. Time to switching DMARD, a measure of effectiveness that includes efficacy and tolerability/safety ${ }^{12}$, was shorter in women, but equivalent after multivariable adjustment. Notably, multivariable models may have been overadjusted by including time-varying DAS, one of the primary reasons for switching therapies. In further evaluation of treatment response, physical function and disease activity trajectories after initiating therapy were mostly similar between men and women. In contrast to the findings in this study, prior studies in the British Society for Rheumatology Biologics Register, DANBIO, and Corrona found that women with early RA were less likely than men to respond to treatment (in these cases, TNFi) ${ }^{10,13}$ or to achieve sustained remission ${ }^{4}$. In established RA, sex differences in treatment response are less apparent $\mathrm{t}^{4,10,11,14}$.

The second important question is why do these sex differences in treatment exist? Unfortunately, this question cannot be answered by the data in this study and often cannot be answered in the observational registries capable of identifying these discrepancies. There are many known factors that affect treatment selection in RA - composite disease activity measure scores (and their individual components), functional status, disease damage, expected efficacy, potential side effects, safety profile, comorbid conditions, fertility and family planning, allergies, medication interactions, need for medication monitoring, cost, and access, among others. Additionally, there are 2 perspectives for evaluating each of these variables, that of the patient and the provider. Thus, treatment selection represents a process of shared decision making, and incorporation of our patients' wishes and desires is imperative. Fortunately, emerging data are providing a better understanding of which factors drive patient and provider treatment choices during shared decision making 15,16 .

So what is most important concerning RA treatment? Is it where we are, i.e., the country where we reside? The country we live in influences which DMARD may be the first prescribed and the access to other DMARD ${ }^{17}$. Is it who we are, i.e., our sex? Females tend to have lower response rates to DMARD, and the current study suggests sex differences in initial treatment patterns in some countries. Or is it where we are going, i.e., the target of treatment? I believe it is the latter. The initial DMARD choice is not as important as adhering to a treat-to-target approach that intensifies the DMARD regimen if the patient is not responding. This approach has been demonstrated in 2 landmark, early RA comparative effectiveness trials. In the Behandel Strategieën (BeSt) trial, there were equivalent 2-year outcomes for patients with RA initiating sequential monotherapy, step-up combination therapy, initial combination therapy with prednisone, or initial combination therapy with infliximab ${ }^{18}$. Similarly, in the Treatment of Early Aggressive Rheumatoid

Personal non-commercial use only. The Journal of Rheumatology Copyright $@$ 2018. All rights reserved 
Arthritis (TEAR) trial, initial combination therapy compared to step-up from MTX monotherapy resulted in equivalent 48-102 week outcomes ${ }^{19}$. So while your initial RA treatment may depend on "where you are" or "who you are," most importantly it is "where you are going" — which should be remission or low disease activity.

\author{
BRYANT R. ENGLAND $\square$, MD, \\ Division of Rheumatology and Immunology, \\ Department of Internal Medicine, \\ University of Nebraska Medical Center (UNMC), \\ and Veterans Affairs Nebraska- \\ Western IA Health Care System, \\ Omaha, Nebraska, USA.
}

Address correspondence to Dr. B.R. England, 983025 Nebraska Medical Center, Omaha, Nebraska 68198-3025, USA. Dr. England receives research support from the UNMC Physician-Scientist Training Program, UNMC Department of Internal Medicine Scientist Development Award, UNMC Mentored Scholars Program, and the Central States-Center for Agricultural Safety and Health. The content of this editorial is solely the responsibility of the author and does not necessarily represent the official views of the US Department of Veterans Affairs.

\section{REFERENCES}

1. Singh JA, Saag KG, Bridges SL Jr., Akl EA, Bannuru RR, Sullivan MC, et al. 2015 American College of Rheumatology guideline for the treatment of rheumatoid arthritis. Arthritis Rheumatol 2016;68:1-26.

2. Smolen JS, Landewe R, Bijlsma J, Burmester G, Chatzidionysiou K, Dougados $\mathrm{M}$, et al. EULAR recommendations for the management of rheumatoid arthritis with synthetic and biological disease-modifying antirheumatic drugs: 2016 update. Ann Rheum Dis 2017;76:960-77.

3. Bergstra SA, Allaart CF, Ramiro S, Chopra A, Govind N, Silva C, et al. Sex-associated treatment differences and their outcomes in rheumatoid arthritis: results from the METEOR register. J Rheumatol 2018;45:1361-6.

4. Jawaheer D, Messing S, Reed G, Ranganath VK, Kremer JM, Louie JS, et al. Significance of sex in achieving sustained remission in the Consortium of Rheumatology Researchers of North America cohort of rheumatoid arthritis patients. Arthritis Care Res 2012;64:1811-8.

5. Sokka T, Toloza S, Cutolo M, Kautiainen H, Makinen H, Gogus F, et al. Women, men, and rheumatoid arthritis: Analyses of disease activity, disease characteristics, and treatments in the QUEST-RA study. Arthritis Res Ther 2009;11:R7.

6. Hallert E, Thyberg I, Hass U, Skargren E, Skogh T. Comparison between women and men with recent onset rheumatoid arthritis of disease activity and functional ability over two years (the TIRA project). Ann Rheum Dis 2003;62:667-70.
7. Tengstrand B, Ahlmen M, Hafstrom I. The influence of sex on rheumatoid arthritis: a prospective study of onset and outcome after 2 years. J Rheumatol 2004;31:214-22.

8. Forslind K, Hafstrom I, Ahlmen M, Svensson B, Group BS. Sex: A major predictor of remission in early rheumatoid arthritis? Ann Rheum Dis 2007;66:46-52.

9. Lesuis N, Befrits R, Nyberg F, van Vollenhoven RF. Gender and the treatment of immune-mediated chronic inflammatory diseases: rheumatoid arthritis, inflammatory bowel disease and psoriasis: an observational study. BMC Med 2012;10:82.

10. Jawaheer D, Olsen J, Hetland ML. Sex differences in response to anti-tumor necrosis factor therapy in early and established rheumatoid arthritis - results from the DANBIO registry. J Rheumatol 2012;39:46-53.

11. Nourisson C, Soubrier M, Mulliez A, Baillet A, Bardin T, Cantagrel $\mathrm{A}$, et al. Impact of gender on the response and tolerance to abatacept in patients with rheumatoid arthritis: results from the "ORA" registry. RMD Open 2017;3:e000515.

12. Aletaha D, Smolen JS. Effectiveness profiles and dose dependent retention of traditional disease modifying antirheumatic drugs for rheumatoid arthritis. An observational study. J Rheumatol 2002;29:1631-8.

13. Hyrich KL, Watson KD, Silman AJ, Symmons DP, British Society for Rheumatology Biologics Register. Predictors of response to anti-TNF-alpha therapy among patients with rheumatoid arthritis: results from the British Society for Rheumatology Biologics Register. Rheumatology 2006;45:1558-65.

14. Couderc M, Gottenberg JE, Mariette X, Pereira B, Bardin T, Cantagrel A, et al. Influence of gender on response to rituximab in patients with rheumatoid arthritis: results from the Autoimmunity and Rituximab Registry. Rheumatology 2014;53:1788-93.

15. Fraenkel L, Nowell WB, Michel G, Wiedmeyer C. Preference phenotypes to facilitate shared decision-making in rheumatoid arthritis. Ann Rheum Dis 2018;77:678-83.

16. Hifinger M, Hiligsmann M, Ramiro S, Watson V, Severens JL, Fautrel B, et al. Economic considerations and patients' preferences affect treatment selection for patients with rheumatoid arthritis: a discrete choice experiment among European rheumatologists. Ann Rheum Dis 2017;76:126-32.

17. Putrik P, Ramiro S, Kvien TK, Sokka T, Pavlova M, Uhlig T, et al. Inequities in access to biologic and synthetic DMARDs across 46 European countries. Ann Rheum Dis 2014;73:198-206.

18. Goekoop-Ruiterman YP, de Vries-Bouwstra JK, Allaart CF, van Zeben D, Kerstens PJ, Hazes JM, et al. Comparison of treatment strategies in early rheumatoid arthritis: a randomized trial. Ann Intern Med 2007;146:406-15.

19. Moreland LW, O'Dell JR, Paulus HE, Curtis JR, Bathon JM, St Clair EW, et al. A randomized comparative effectiveness study of oral triple therapy versus etanercept plus methotrexate in early aggressive rheumatoid arthritis: the treatment of early aggressive rheumatoid arthritis trial. Arthritis Rheum 2012;64:2824-35.

J Rheumatol 2018;45:1341-3; doi:10.3899/jrheum.180395 